\title{
Where Are the Women Editors?
}

\author{
Laura Weiss Roberts
}

Received: 23 May 2014 / Accepted: 27 May 2014 / Published online: 8 July 2014

(C) Academic Psychiatry 2014

I have been a woman for a long time, a physician for quite a while, and chairman and an editor in chief for this academic journal for more than a decade. Being the only woman "in the room" for much of my career, I accept that I must have my share of unconscious bias regarding gender and academic medicine, no matter how hard I have worked to address the issues of diversity and disparities in medicine. The fullness of the phenomenon of unconscious bias was nevertheless made clear to me very recently when I "realized"-for the first time- how few current academic medical journal editors are women.

Think for a minute, Dear Reader. Where are the woman editors in medicine?

Consider the following observations: of the top 20 highest-impact psychiatry science journals, there are 24 editors in chief publicly listed on the Web of Science (apps.webofknowledge.com) — and all 24 are men. Of the top 20 highest-impact journals for education in the "scientific disciplines" on the Web of Science, there are 20 editors in chief publicly listed, and only 4 are women. Four of 44, or $9 \%$, of editors in chief for top impact journals in psychiatry and science education-fields relevant to the readers of Academic Psychiatry - are women. Consider other highly influential journals in medicine and science, such as the New England Journal of Medicine (impact factor=52), Lancet (impact factor $=39$ ), Nature (impact factor $=38$ ), and $J A M A$ (impact factor=30); for each, the editors in chief are men. In 2009, Science (impact factor=31) appointed Marcia McNutt as editor in chief, the first woman editor since the journal was established in 1880 .

To provide additional context, there are more than 242,000 women physicians in the USA, including almost 50,000

L. W. Roberts $(\bowtie)$

Stanford University School of Medicine, Stanford, CA, USA

e-mail: RobertsL@stanford.edu female medical school faculty members and 6,369 women who serve as full professors. Nearly one third, $31 \%$, of all physicians in the AMA Physician Masterfile are women [1]. In our field, $46 \%$ of academic psychiatrists are women, and $25 \%$ of full professors in psychiatry are women [2]. Moreover, $30 \%$ of NIH investigators are women [3]. Presumably, many of these highly accomplished senior professors and scientists have the analytic and literary strengths needed to fulfill the responsibilities as an editor in chief. Given their underrepresentation, we can infer that there is some interference or disruption along the career development path for women who may seek to become academic journal editors.

Instead of thinking about all the barriers to attaining this professional role, however, perhaps it is of value to consider the attributes and the string of very fortunate events that lead to becoming an editor in chief. A love of language, a desire to shepherd excellent scholarship, and a willingness to work hard and generatively - these are necessary but not sufficient attributes for the editor role. Experiences as an author, a reviewer, and a guest editor are invaluable. Timing helps too, because editor roles for academic journals do not open up very often.

From my own experience, great mentors made the critical difference in supporting my "calling" to the work as an editor in medicine. One mentor gave me the courage to serve as a guest editor for a special issue of a major journal when I was a first-year psychiatry resident [4]. Editors in chief of many different journals have across time given me the chance to work on special theme issues with them, providing much guidance and wisdom along the way [5-12]. Another mentor gave me extraordinary opportunities to learn about editing and stepped in at just the right time with just the right advice ("something worth having is worth fighting for") when I was feeling a bit dispirited by the "hard ball" process associated with the national selection of a journal editor. I doubt that these mentors were thinking about my gender; they were thinking simply about how to support or enhance my ability 
to perform the work. These mentors helped me learn the mechanics of the publishing process, and more importantly, they modeled how to live the role- how to fulfill editor duties that involve expertise, mature judgment, and professionalism.

And all editors know, once they get their positions, that their success is based in the quality of their colleagues: authors, reviewers, fellow editors, editorial assistants, and members of their editorial boards. These individuals generate, refine, and advance the scholarship of the field. These colleagues often work selflessly and unrecognized, and together they help ensure the rigor of the work that is ultimately published. This year in Academic Psychiatry, we are running a series of wonderful essays by editors in chief, including Andrés Martin [13], Jonathan Borus [14], David Dunner [15], and Howard Goldman [16], in which they reflect on their work and allow our readers to peek "behind the curtain" to get a glimpse of journal leadership. In each essay, the value of colleagues and collegiality is evidenced. Passion, serendipity, teachers, and friends, as with all of academic medicine, are all important as we make our way in the special professional role of an editor.

My recognition of the underrepresentation of women as editors in chief was slow, I suspect, because journal and book editors in chief who are extraordinary women-for example, Nancy Andreasson, Addeane Caelleigh, Catherine DeAngelis, and Carol Nadelson - had shaped much of my earlier experience in academic medicine. These women served along with their male colleagues to move the fields of psychiatry, medical education, and clinical medicine forward, and they served as superb role models for early-career physicians. The presence of these great women in medicine made becoming an editor in chief seem somehow possible. Does this special professional work now seem less "possible" to earlycareer physicians who are underrepresented, including women, I wonder?

My hope in writing this essay is that our early-career academic colleagues will envision themselves in influential roles in medicine, including as journal editors, even if they do not "see" someone who looks like them in the job already. Looking ahead, nearly half of medical students are women [17], and the majority of those entering academic psychiatry, i.e., instructors and assistant professors, are women [2]. Many of these women, moreover, are international origin and underrepresented minority individuals, which introduces additional perceived and real barriers to attaining roles of influence in academic medicine [2]. I hope that our early-career colleagues, especially those whose backgrounds differ from current leaders, will step forward and that they will be welcomed.

Diversity in editors, as in medicine and society more broadly, may be framed in ethical terms as a justice issue, but the motivation behind this essay is different. The field of academic psychiatry needs all of us to fulfill its responsibilities in society and to flourish as a profession. We are a small troupe entrusted with creating a better future for all people whose lives are affected by mental illness through our combined efforts in science, clinical innovation, education and mentorship, community engagement, and leadership. Many roles, including as editors in chief, go with this set of important and interdependent academic missions. "Hemi-neglect" of the intellectual contribution and richness of thought, perspectives, and experience offered by what is essentially half of the talented people of our profession is simply unwise. So, let us all work together, shall we, as colleagues and mentors to help create the string of very fortunate events needed to advance the aspirations of our very special early-career colleagues throughout academic psychiatry.

And perhaps, in time, we will also find ourselves with a few more women editors.

Disclosures The author owns Terra Nova Learning Systems and also receives royalties from books she has authored and edited.

\section{References}

1. American Medical Association: AMA Physician Masterfile. Available at http://www.ama-assn.org/ama/pub/about-ama/ physician-data-resources/physician-masterfile.page?. Accessed May 15, 2014.

2. Association of American Medical Colleges: Women in academic medicine statistics and medical school benchmarking, 2011-2012. Available at https://www.aamc.org/members/gwims/statistics/. Accessed May 15, 2014.

3. National Institutes of Health Office of Extramural Research: 2011 success rates, applications, and investigators. Available at http:// nexus.od.nih.gov/all/2012/01/13/2011-success-rates-applicationsand-investigators/. Accessed May 15, 2014.

4. Roberts LW, Miles SH: Teaching medical ethics [special issue]. Acad Med 1989; 64(12).

5. Roberts LW, McCarty T: Education of psychiatry residents in ethics [special issue]. Acad Psychiatry 1996; 20(3).

6. Roberts LW, Bogenschutz M: Preparing the next generation of psychiatric researchers [special issue]. Acad Psychiatry 2001; 25(1).

7. Roberts LW, Krystal J: Ethics of psychopharmacological research [special issue]. Psychopharmacology 2003; 171(1).

8. Roberts LW, Dunn LB: Ethics of schizophrenia research [special issue]. Schizophr Bull 2006; 32(1).

9. Roberts LW, Clayton R, McBride D, Hartsock P: Drug abuse research in rural communities: current knowledge and future directions [special issue]. J Rural Health 2007; Volume 23 Supplement.

10. Roberts LW, Hoop JG: Ethics in psychiatry: a review [special issue]. Psychiatr Clin N Am 2009; 32(2).

11. Roberts LW, Coverdale JH: Topics in psychiatric ethics [special issue]. Int Rev Psychiatry 2010; 22(3)

12. Roberts LW: Psychiatric ethics [special issue]. Am J Bioeth Prim Res 2011;2(4)

13. Martin A. World of wordcraft: on scientific editing. Acad Psychiatry. 2014;38(1):86-9.

14. Borus J. Editors and authors: two halves of a whole. Acad Psychiatry. 2014;38(2):224-5. 
15. Dunner DL. Being an editor of a psychiatric journal. J Acad Psychiatry. 2014. doi:10.1007/s40596-014-0107-x.

16. Goldman H. Curating psychiatric services. Acad Psychiatry. 2014. doi:10.1007/s40596-014-0098-7.

17. Association of American Medical Colleges: Diversity in medical education: facts \& figures 2012. Available at https://members.aamc.org/eweb/
DynamicPage.aspx?Action=Add\&ObjectKeyFrom=1A83491A-98534C87-86A4-F7D95601C2E2\&WebCode=PubDetailAdd\&DoNotSave $=$ yes $\&$ ParentObject $=$ CentralizedOrderEntry $\&$ ParentDataObject $=$ Invoice\%20Detail\&ivd_formkey=69202792-63d7-4ba2-bf4ea0da41270555\&ivd prc prd key=E1A7507B-F47B-40D0-89469ADBAB417F3E. Accessed May 15, 2014. 